\begin{tabular}{|c|c|c|}
\hline Donart & Case Rep Gastroenterol 2018; & \\
\hline Ogy & $\begin{array}{l}\text { DOI: } 10.1159 / 000493253 \\
\text { Published online: November 28, } 2018\end{array}$ & $\begin{array}{l}\text { (c) } 2018 \text { The Author(s) } \\
\text { Published by S. Karger AG, Basel } \\
\text { www.karger.com/crg }\end{array}$ \\
\hline & $\begin{array}{l}\text { This article is licensed under the } \\
\text { NoDerivatives } 4.0 \text { International License } \\
\text { OpenAccessLicense). Usage and distr } \\
\text { distribution of modified material requir }\end{array}$ & $\begin{array}{l}\text { Jmmons Attribution-NonCommercial- } \\
\text { ND) (http://www.karger.com/Services/ } \\
\text { commercial purposes as well as any } \\
\text { rmission. }\end{array}$ \\
\hline
\end{tabular}

Attribution-NonCommercialOpenAccessLicense). Usage and distribution for commercial purposes as well as any distribution of modified material requires written permission.

\title{
Intrabiliary Migrated Clips and Coils as a Nidus for Biliary Stone Formation: A Rare Complication following Laparoscopic Cholecystectomy
}

\author{
Anne M. Schreuder ${ }^{a}$ Thomas M. van Gulik ${ }^{a} \quad$ Erik A.J. Rauws \\ aDepartment of Surgery, Amsterdam UMC, University of Amsterdam, Amsterdam, The \\ Netherlands; ${ }^{b}$ Department of Gastroenterology, Amsterdam UMC, University of \\ Amsterdam, Amsterdam, The Netherlands
}

\section{Keywords}

Clip migration · Foreign body migration · Cholecystectomy · Endoscopic retrograde cholangiopancreatography · Bile duct injury

\begin{abstract}
Clips inserted during laparoscopic cholecystectomy (LC) may migrate into the biliary system and function as a nidus for the formation of gallstones. Here, we present a series of 4 patients who presented with this rare complication 5-17 years after LC. All 4 patients presented with symptomatic choledocholithiasis with biochemical and radiological signs of biliary obstruction. Three patients also had fever and infectious parameters, compatible with concurrent cholangitis. All patients successfully underwent endoscopic retrograde cholangiopancreatography (ERCP) with papillotomy and stone extraction. Patients with cholangitis also had antibiotic treatment. In 3 patients, obstruction of the common bile duct was caused by a single, relatively large stone that had formed around a clip (supposedly the cystic duct clip). In 1 patient, multiple stones had formed around an intrabiliary migrated cluster of coils that had been used for arterial embolization of a pseudo-aneurysm of the right hepatic artery. In conclusion, surgical clips and coils can migrate into the biliary tract and serve as a nidus for the formation of bile duct stones. Although rare, this complication should caution surgeons not to place clips "at random" during cholecystectomy. Patients with this rare complication are best managed by ERCP in combination with sphincterotomy and stone extraction.
\end{abstract}




\section{Introduction}

Cholecystectomy is one of the most frequently performed abdominal surgeries, with laparoscopic cholecystectomy (LC) being the gold standard to date [1, 2]. Generally, surgical clips are used in this laparoscopic procedure to close the cystic duct and secure the cystic artery. Usually only 1 or 2 clips are used to this end. However, sometimes clips are also liberally used to achieve hemostasis. This is not without risk, as improper placement of clips may lead to bile leakage, bile duct injury, or vascular injury [2].

Like other foreign bodies, surgical clips can migrate into surrounding tissues. Migration of cholecystectomy clips towards the duodenum has been reported, causing a duodenal ulcer or giving rise to a choledochoduodenal fistula [3]. Migration into the adjacent biliary ducts is a rare phenomenon, first reported in 1979 [4]. Intrabiliary migrated clips can serve as a nidus for the formation of gallstones, potentially causing obstruction and cholangitis. Herein we present a series of 4 patients who presented with this rare complication many years after cholecystectomy.

\section{Case Report}

Case A

Patient A, a 66-year-old female patient, had a history of hepatitis B. Because of symptomatic cholecystolithiasis she underwent LC at the age of 60. Her hospital admission was prolonged because of a transient postoperative cholestasis, for which no cause was found, and which was interpreted as a passed common bile duct (CBD) stone.

Six years later, at a regular visit for follow-up of her hepatitis B, elevated liver enzymes were found: bilirubin $18 \mu \mathrm{g} / \mathrm{L}, \gamma$-glutamyl transpeptidase (GGT) $343 \mathrm{IU} / \mathrm{L}$, alkaline phosphatase (AF) $120 \mathrm{IU} / \mathrm{L}$, aspartate aminotransferase (ASAT) $50 \mathrm{IU} / \mathrm{L}$, and alanine aminotransferase (ALAT) 66 IU/L. Abdominal ultrasound showed dilated intrahepatic bile ducts and a hyperechogenic structure in the liver hilum. Subsequent magnetic resonance cholangiopancreatography (MRCP) showed two strictures: one in the common hepatic duct just below the hilum, and one in the CBD at the level of the cystic duct. No obvious stones were seen. She was referred to our center for endoscopic treatment of this biliary stenosis.

An endoscopic retrograde cholangiopancreatography (ERCP) was performed. Cholangiography showed a severe subhilar stenosis in the vicinity of 3 surgical clips. The stenosis was dilated using an 8-mm balloon catheter and a single, plastic endoprosthesis was inserted. Four weeks later, the patient was seen in the emergency room because of upper abdominal pain and subfebrile temperature. Laboratory results showed an elevated C-reactive protein (CRP) of $48 \mathrm{mg} / \mathrm{L}$ and signs of cholestasis (bilirubin $21 \mu \mathrm{mol} / \mathrm{L}$, GGT $866 \mathrm{IU} / \mathrm{L}, \mathrm{AF} 205 \mathrm{IU} / \mathrm{L}$, ASAT $56 \mathrm{IU} / \mathrm{L}$, ALAT $101 \mathrm{IU} / \mathrm{L}$ ). The patient was admitted under the suspicion of cholangitis and was treated with intravenous antibiotics (Ciproxin and Augmentin). During ERCP, a filling defect around one of the clips was observed (Fig. 1a). Using a Dormia basket, this clip, around which a 10-mm large stone had formed, could be removed (Fig. 1b). Another balloon dilatation was performed, and three plastic stents were inserted.

After this, the patient underwent two more ERCPs with dilatation and progressive stenting, and after a period of 6 months all stents could be removed leaving a patent bile duct. She was last seen for follow-up 2 years later, with no signs of cholestasis. 
Case $B$

Patient B, a 63-year-old male, was referred to our center after he sustained a bile duct injury during an explorative laparotomy performed under the suspicion of a duplicate gallbladder. The patient had undergone LC 4 years earlier, but experienced recurrent upper abdominal pain. No duplicate gallbladder was found, but the procedure resulted in partial injury to the CBD and the right hepatic duct. Treatment of this bile duct injury consisted of percutaneous drainage of a biloma and intra-abdominal abscesses followed by endoscopic stent treatment for a period of 15 months.

The patient presented at the emergency room 8 years later, with complaints of upper abdominal pain, jaundice, nausea, and fever $\left(39.2^{\circ} \mathrm{C}\right)$. Laboratory results showed cholestasis and elevated infectious parameters, with a leukocyte count of $16 \times 10^{9} / \mathrm{L}$, CRP of $161 \mathrm{mg} / \mathrm{L}$, bilirubin of $103 \mu \mathrm{g} / \mathrm{L}$, ASAT $358 \mathrm{IU} / \mathrm{L}$, ALAT $390 \mathrm{IU} / \mathrm{L}$, AF $138 \mathrm{IU} / \mathrm{L}$, and GGT $861 \mathrm{IU} / \mathrm{L}$. Abdominal ultrasound showed dilated intrahepatic bile ducts, while the distal CBD could not be visualized due to air in the intestines. The patient was admitted under the suspicion of cholangitis and received intravenous antibiotics (ceftriaxone and gentamicin). ERCP showed a large stone in the distal CBD, formed around a clip, which was extracted using a Dormia basket (Fig. 1c, d). The patient recovered well and had no recurrent symptoms during 4 years of follow-up.

Case $C$

Patient C, a 50-year-old male, underwent LC at the age of 33 because of symptomatic choledocholithiasis. The postoperative course was uneventful. However, 17 years later, he presented himself to the emergency room with colic pains in the right upper abdomen, similar to the pains he used to have when he suffered from gallstones. He did not present with fever or jaundice on admission. Laboratory results showed elevated cholestatic parameters with bilirubin of $77 \mu \mathrm{g} / \mathrm{L}$, ASAT $41 \mathrm{IU} / \mathrm{L}$, ALAT $95 \mathrm{IU} / \mathrm{L}$, AF $277 \mathrm{IU} / \mathrm{L}$, and GGT 587 IU/L. Infectious parameters were elevated, with a leucocyte count of $18 \times 10^{9} / \mathrm{L}$ and a CRP of $237 \mathrm{mg} / \mathrm{L}$. MRCP showed a stone in the distal CBD with dilated intra- and extrahepatic bile ducts. An attempt at ERCP failed because of failed cannulation, after which the patient was referred to our institution. On the suspicion of cholangitis, the patient was treated with intravenous antibiotics (cefuroxime).

At repeat ERCP in our institution, the CBD could be cannulated. Cholangiography showed a dilated CBD with multiple small stones and 1 intrabiliary clip; multiple clips were seen at the site of the cholecystectomy (Fig. 1e). After balloon dilatation of the distal CBD, the stones, together with sludge and clip, could be extracted (Fig. 1f). The patient recovered well and had no recurrence of symptoms.

Case D

Patient D, a 48-year-old female, underwent LC on the indication of symptomatic cholecystolithiasis. The procedure was complicated by a complete transection of the CBD. Initial treatment of this bile duct injury consisted of percutaneous drainage of a biloma and restoration of bile duct continuity by percutaneous-endoscopic rendezvous procedure [5], followed by a period of progressive stenting. Because of the emergence of a pseudoaneurysm of the right hepatic artery she underwent coiling of the right hepatic artery 4 weeks after LC. After a period of 8 months, the last stents could be removed, leaving a patent bile duct.

The patient was seen for follow-up at our outpatient department 5 years after LC. At this visit, she reported having intermittent colic pains over the previous few weeks, without jaundice, discolored stools, or fever. Laboratory results showed signs of cholestasis with an AF of 436 IU/L, GGT 1,463 IU/L, ASAT 87 IU/L, and ALAT 77 IU/L. The patient underwent ERCP, 
during which time a recurrent stricture of the CBD was seen, along with multiple filling defects and multiple coils in the biliary system (Fig. 1g). The stricture was dilated using a balloon catheter, and the stones and mobile coils were extracted using a Dormia basket and crusher (Fig. 1h). A fully covered metal stent was inserted, and the patient started medical treatment for cholestasis with Ursochol. This stent was removed after 6 months, leaving a slight stenosis of the bile duct. To date, 2.5 years later, the patient has been free of complaints.

\section{Discussion}

Migration of surgical clips is a rare complication following LC. In this series of 4 patients, ERCP with sphincterotomy and stone extraction with a Dormia basket was successful in all cases.

Intrabiliary migration of foreign bodies is a rare complication and the literature only consists of case reports. Besides surgical clips, nonabsorbable sutures, coils for arterial embolization, ingested fish bones and toothpicks, and remnants of draining tubes or stents have been reported to migrate into the biliary tract [6-8]. A literature review of 69 cases of intrabiliary migrated surgical clips showed ERCP to be the appropriate treatment, with a success rate of 85\% [9]. When ERCP fails or is impossible, for example due to altered gastrointestinal anatomy after abdominal surgery, percutaneous transhepatic cholangiography with stone extraction may be attempted [10]. Alternatively, surgical exploration of the CBD may be necessary to remove obstructing objects and bile stones [9].

Clinical presentation is similar to that of primary choledocholithiasis, with colic pains and obstructive jaundice, sometimes accompanied by signs of cholangitis. The risk of developing cholangitis may be increased due to the presence of an intrabiliary foreign body, as was the case in 3 out of 4 patients presented here. Radiological evaluation usually consists of abdominal ultrasound, magnetic resonance imaging, or ERCP. On ERCP, a filling defect with a radiopaque line in the center may be seen. This remarkable radiographic appearance has also been referred to as "cat's eye calculus" [11].

The exact pathophysiology of foreign body migration is not completely understood but is thought to be related to inadequate clip placement, (sterile) inflammation, and necrosis [9, 12]. Notably, 3 out of 4 patients in this case series had a history of complicated LC. This supports the theory that local inflammation by (clinical or subclinical) bile leakage induces the process of foreign body migration.

The use of clips seems indispensable during LC. However, some surgeons advocate clipless surgery by ultrasonic dissection of the cystic duct and cystic artery [13, 14]. Others suggest the use of absorbable clips [15]. Preliminary results of small trials are promising, but their safety and efficacy has still to be confirmed.

In conclusion, surgical clips and coils can migrate into the biliary tract, where they may function as a nidus for the formation of bile duct stones. Clinical presentation is similar to the regular presentation of bile duct stones. Patients are best managed by ERCP with sphincterotomy and stone extraction. Although rare, this complication cautions surgeons not to place clips "at random" during cholecystectomy. In the future, clipless surgery might eliminate this rare phenomenon. 


\section{Statement of Ethics}

The authors have no ethical conflicts to disclose.

\section{Disclosure Statement}

The authors have no conflicts of interest to declare.

\section{Author Contributions}

A.M. Schreuder analyzed the cases and drafted the manuscript. T.M. van Gulik critically revised the manuscript. E.A.J. Rauws critically revised the manuscript and performed all ERCPs in the presented patients. All authors read and approved the final version of this manuscript.

\section{References}

1 Csikesz NG, Singla A, Murphy MM, Tseng JF, Shah SA. Surgeon volume metrics in laparoscopic cholecystectomy. Dig Dis Sci. 2010 Aug;55(8):2398-405.

2 Overby DW, Apelgren KN, Richardson W, Fanelli R; Society of American Gastrointestinal and Endoscopic Surgeons. SAGES guidelines for the clinical application of laparoscopic biliary tract surgery. Surg Endosc. 2010 Oct;24(10):2368-86.

3 Hong T, Xu XQ, He XD, Qu Q, Li BL, Zheng CJ. Choledochoduodenal fistula caused by migration of endoclip after laparoscopic cholecystectomy. World J Gastroenterol. 2014 Apr;20(16):4827-9.

4 Walker WE, Avant GR, Reynolds VH. Cholangitis with a silver lining. Arch Surg. 1979 Feb;114(2):214-5.

5 Schreuder AM, Booij KA, de Reuver PR, van Delden OM, van Lienden KP, Besselink MG, et al. Percutaneousendoscopic rendezvous procedure for the management of bile duct injuries after cholecystectomy: shortand long-term outcomes. Endoscopy. 2018 Jun;50(6):577-87.

6 Bent CK, Wright L, Dong PR. "Coildocholithiasis”-Common Bile Duct Obstruction Secondary to Migration of Right Hepatic Artery Pseudoaneurysm Coils. J Vasc Interv Radiol. 2016 Nov;27(11):1741-3.

7 Sakakida T, Sato H, Doi T, Kawakami T, Nakatsugawa Y, Nishimura K, et al. A Bile Duct Stone Formation around a Fish Bone as a Nidus after Pancreatoduodenectomy. Case Rep Gastroenterol. 2018 Feb;12(1):6975.

8 Brunaldi VO, Brunaldi MO, Masagao R, Silva C, Masuda H, Brunaldi JE. Toothpick Inside the Common Bile Duct: A Case Report and Literature Review. Case Rep Med. 2017;2017:5846290.

9 Chong VH, Chong CF. Biliary complications secondary to post-cholecystectomy clip migration: a review of 69 cases. J Gastrointest Surg. 2010 Apr;14(4):688-96.

10 Singh MK, Kinder KZ, Braverman SE. Transhepatic Management of a Migrated Intraductal Surgical Clip after Cholecystectomy and Gastrectomy. J Vasc Interv Radiol. 2015 Dec;26(12):1866.

11 Wu WC, Katon RM, McAfee JH. Endoscopic management of common bile duct stones resulting from metallic surgical clips (cat's eye calculi). Gastrointest Endosc. 1993 Sep-Oct;39(5):712-5.

12 Kitamura K, Yamaguchi T, Nakatani H, Ichikawa D, Shimotsuma M, Yamane T, et al. Why do cystic duct clips migrate into the common bile duct? Lancet. 1995 Oct;346(8980):965-6.

13 Hüscher CG, Lirici MM, Di Paola M, Crafa F, Napolitano C, Mereu A, et al. Laparoscopic cholecystectomy by ultrasonic dissection without cystic duct and artery ligature. Surg Endosc. 2003 Mar;17(3):442-51.

14 Wills E, Crawford G. Clipless versus conventional laparoscopic cholecystectomy. J Laparoendosc Adv Surg Tech A. 2013 Mar;23(3):237-9.

15 Yang CP, Cao JL, Yang RR, Guo HR, Li ZH, Guo HY, et al. Efficacy of electrocoagulation in sealing the cystic artery and cystic duct occluded with only one absorbable clip during laparoscopic cholecystectomy. J Laparoendosc Adv Surg Tech A. 2014 Feb;24(2):72-6. 


\section{Case Reports in Gastroenterology}
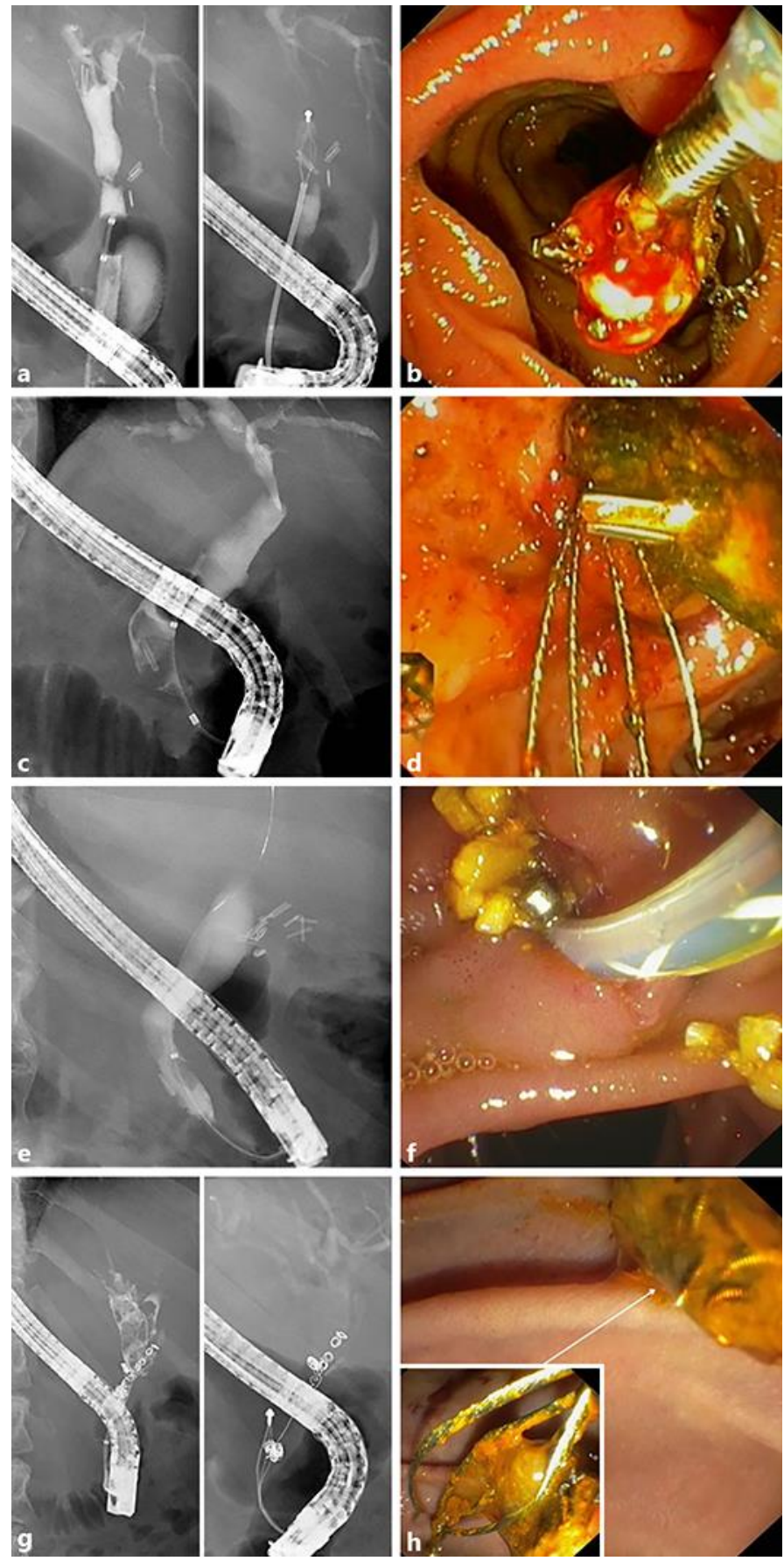

Fig. 1. ERCP images of the presented cases. a Cholangiography of patient A, showing a large filling defect in the right hepatic duct around a radiopaque line. This concrement was extracted using a Dormia basket. b Extraction of a concrement formed around a surgical clip in patient A. c Cholangiography of patient B, showing a filling defect around a radiopaque line in the distal common bile duct. $\mathbf{d}$ Extraction of a large concrement formed around a clip in patient B. e Cholangiography of patient $\mathrm{C}$, showing multiple small concrements in the common bile duct. Also, multiple clips (+/-10) can be seen at the site of cholecystectomy. f Extraction of multiple concrements and a surgical clip in patient C. $g$ Cholangiography of patient D, showing a stricture of the common bile duct, multiple filling defects, and multiple coils appearing to have intrabiliary location. $\mathbf{h}$ Extraction of concrements formed around a cluster of coils in patient D. 